\title{
Dr. Elisabeth Kubler-Ross' Stages of Dying and Phenomenology of Grief
}

\author{
K MAHMOOD \\ Department of Philosophy. G.C. University, Lahore \\ Correspondence to Mr. Kaiser Mahmood. Lecturer.
}

Birth and death are both natural events but the emotional impact and the personal meanings of these events are vastly different. Birth may be anticipated with excitement and optimism, while the reality of death may be avoided and been denied. Elisabeth Kubler-Ross has been a pioneer in arousing popular and medical interest in the subject of death and dying. A physician who worked with dying patients and encouraged them to talk about themselves and their feelings toward their impending death. She found that most of the patients she had contact with welcomed the opportunity to speak openly about their conditions. After speaking with some 500 terminally ill patients, KublerRoss proposed that there were five stages in coming to terms with death: denial, anger, bargaining, depression and acceptance.

(i) Denial

In the denial stage, the person denies the possibility of death and searches for other, more promising opinions and diagnoses. This is a common reaction to terminal illness. However, denial is usually only a temporary defence.

As Kubler-Ross writes:

"Among the over two hundred dying patients we have interviewed, most reacted to the awareness of a terminal illness at first with the statement". No, not me, it cannot be true"l.

(ii) Anger

The second stage of dying is anger in which the dying person recognized that denial can no longer be maintained. Denial often gives way to anger, resentment, range and envy.

Kubler-Ross writes:

"When the first stage of denial cannot be maintained any longer, it is replaced by feelings of anger, rage, envy and resentment. The logical next question becomes: "Why me"?? ?

\section{(iii) Bargaining}

Bargaining is the third stage of dying in which the person develops the hope that death can somehow be posiponed or delayed. Here the individual tries to think of ways to postpone death. Most of these bargains are made with God. The person makes some kind of deal in which, if spread, he or she will undertake some unusual sacrifice to help others.

(iv) Depression

When the bargaining fails, depression and hopelessness take hold. The person in the depression stage mourns both for the losses that have already occurred and the death and separation from family and friends to come.
All these reasons for depressions are well known to everybody who deals with patients ${ }^{3}$. The dying person may become silent refuse visitors and spend much of the time crying or grieving.

\section{(v) Acceptance}

In the final stage of acceptance the person accepts and awaits his or fate quietly. Acceptance should not be mistaken for a happy stage. It is almost void of feelings ${ }^{4}$. In this stage the person develops a sense of peace, an acceptance of one's fate and in many cases, a desire to be left alone. In this stage, feelings and physical pain may be virtually absent.

Bereavement is a universal experience. The loss of any object or person with whom one has a significant relationship leads to grief, a complex emotional response including sadness, anger, and guilt. It is an unavoidable accompaniment of attachment to anyone or anything. Bereavement is part of the price of love ${ }^{5}$. Bereavement signifies a force that comes from outside as a violent, destructive action taken against us.

The term 'grief process' refers to the inner turmoil that follows bereavement and the individual's subsequent adaptation to the new situation ${ }^{6}$. Grief is the emotional numbness, despair, sadness and loneliness that accompany the loss of some one we love. Grief is not a simple emotional state but rather a complex, evolving process with multiple dimensions.

Following characteristics are common in grief;

(i) Grief is a process, not an event.

(ii) Grieving takes time-usually longer than expected or hope.

(iii) Grief is energy-consuming and exhausting ${ }^{7}$. Now, I shall discuss the various forms of grief.

\section{Anticipatory Grief}

Anticipatory grief involves grief reactions brought on by the slow dying of a loved one through injury, illness. In other words, a serious illness precedes the death and these involved anticipate the loss that is inevitable. This experience is called anticipatory grief.

\section{Acute Grief}

Sometimes, a loved one dies suddenly as a result of heart attack or is killed in an accident. At this situation feelings of hostility and irritability are directed at God and fate. This is called acute grief.

As with Kubler-Ross's stage of dying are not absolute and the grieving stages do not prescribe a correct course of grief. Dr. Wayne A. Payne has discussed the 
rrieving process in the four phases, each of which varies in iength and form in each individual:

\section{(i) Internalization Of The Deceased Person's Image}

By forming an idealized mental picture of the dead person, the grieving person is freed from death too quickly with the reality of the death.

\section{(ii) Intellectualization Of The Death}

Mental processing of the death and the events leading uif to its occurrences move the grieving person to a clear ur derstanding that death has occurred.

(iii) Emotional Reconciliation

During this third and often delayed phase, the grieving person allows conflicting feelings and thoughts to be expressed and eventually reconciled with the reality of the death.

\section{(iv) Behavioral Reconciliation}

Finally, the grieving person can comfortably return to a 1 fe in which the death has been fully reconciled. The survivor establishes old routines and adopts new patterns of livening where necessary. The grieving person has largely recovered ${ }^{3}$.

Grief and mourning are closely related. But if we wished to distinguish between the two, we might say that grief is the feeling of loss we experience as a result of a death and mourning is the process of incorporating that loss into our lives. In western cultures, conventional forms of mourning behavior have included wearing black clothes of subdued colors and if the deceased was a public figure, flying the national flag at half-mast. In the United States today, mourning behavior is generally much less formal than among some other cultures or than it was in the past. Much attention has been paid to mourning in recent years in an effort to understand and explain what it involves. Researchers proposed that mourning involves four phases:

(i) Shock and numbness

(ii) Yearning and searching

(iii) Disorganization and despair

(iv) Reorganization?
Funerals and mourning customs help to strengthen and reaffirm the solidarity of the family and the social group and to reconstitute them. There are therapeutic rites for the living, as well as commemorative and propitiatory rites for the dead. Funerals rituals can help provide a sense of closure on the deceased's life and thereby aid integration of the loss into the ongoing lives of survivors. With the help of family and friends, most bereaved people are able to work through their losses and come through the crisis to resume a normal life. They do not forget the dead person, of course, and they may have recurrent bouts of sadness, particularly around special times like birth days and holidays. In grief therapy, professional therapists focus on helping bereaved people express their sorrow and their feelings of loss and guilt, of hostility and anger. They encourage their clients to review their relationships with the deceased and to integrate the fact of the person's death into their lives so that they can be freed to develop new relationships and new ways of acting with surviving friends and relatives.

\section{References:}

1. Kubler-Ross, Elisabeth, On Death and Dying, 1969 Macmillan, New York, P.34.

2. Ibid, P.44.

3. Ibid, P.76.

4. Ibid, P.100.

5. Simpson, Michael A. The Facts of Death: A Complete Guide for Being Prepared, 1979, Prentice-Hall, Inc. New Jersey P.229-30.

6. Rees, Dewi, Death and Bereavement: The Psychological, Religious and Cultural Interfaces, 1997, Whurr Publishers, Ltd., London, P. 109.

7. Isobel Bremner, 'Reaction to Loss'. In Medicine: The Continuously Updated Resource of Clinical Medicine, Finlay, Ilora G. (editor) Vol: 32: 4, 2004 UK.

8. Payne, Wayne A. \& Hahn, Dale B. Understanding Your Health, $7^{\text {th }}$ edition, McGraw Hill, London, P.655.

9. Corr, Charles A. \& Nabe, Clyde M. Death and Dying, Life and Living, $3^{\text {rd }}$ edition, 2000, Wadsworth, USA, P.221. 